\title{
Detection of Brain Cancer from MRI Images using Neural Network
}

\author{
Mohammad Badrul Alam \\ Miah \\ Department of Information and \\ Communication Technology \\ Mawlana Bhashani Science \\ and Technology University \\ Santosh, Tangail - 1902, \\ Bangladesh
}

\author{
Kulsum Akter Kana \\ Department of Information and \\ Communication Technology \\ Mawlana Bhashani Science \\ and Technology University \\ Santosh, Tangail - 1902, \\ Bangladesh
}

\author{
Afroza Akter \\ Department of Information \& \\ Communication Technology \\ Mawlana Bhashani Science \& \\ Technology University \\ Santosh,Tangail-1902, \\ Bangladesh
}

\begin{abstract}
Magnetic Resonance imaging (MRI) is a test that uses a magnetic field and pulses of radio wave energy to make pictures of organs and structures inside the body. MRI can detect a variety of conditions of the brain such as cysts, tumors, bleeding, swelling, developmental and structural abnormalities, infections, inflammatory conditions, or problems with the blood vessels. It can detect the damage of brain caused by an injury or a stroke. So, the proposed system use Magnetic Resonance Imaging images which is preprocessed by using filtering technique. Then some important features has been extracted as GLCM feature, Entropy, Moment features, area, mean, standard deviation, correlation coefficient features has been calculated. Then the proposed system has been trained the Neural Network and tested with known brain images. Then the accuracy of the proposed system has been measured which is very much effective than other existing methods.
\end{abstract}

\section{Keywords}

Brain Cancer, GLCM, Moment Feature, Neural Network, Classification, Preprocessing.

\section{INTRODUCTION}

The brain is an organ that serves as the center of the nervous system in all vertebrate and most invertebrate animals.

Only a few invertebrates such as sponges, jellyfish and starfish do not have a brain. The brain is an organ that serves as the center of the nervous system in all vertebrate and most invertebrate animals. Only a few invertebrates such as sponges, jellyfish and starfish do not have a brain. The brain is located in the head, usually close to the primary sensory organs for such senses as vision, hearing, balance, taste and smell [1]. In a typical human, the cerebral cortex (the largest part) is estimated to contain 15-33 billion neurons, each connected by synapses to several thousand other neurons.

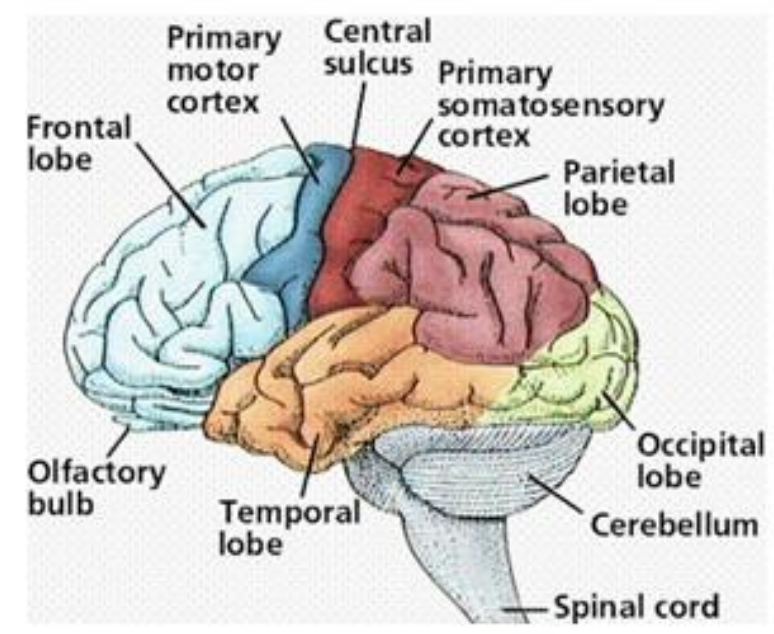

Fig 1: The overall structure of brain

These neurons communicate with one another by means of long protoplasmic fibers called axons, which carry trains of signal pulses called action potentials to distant parts of the brain or body targeting specific recipient cells.

Although brain is most important part of our body as it is the center of our thoughts and also controls the overall parts of our body. But nowadays, brain tumor is common disease among children and adults [1].

The signs and symptoms of a brain tumor vary greatly and depend on the brain tumor's size, location and rate of growth. General signs and symptoms caused by brain tumors may include:

- New onset or change in pattern of headaches

- Headaches that gradually become more frequent and more severe

- Unexplained nausea or vomiting

- Vision problems, such as blurred vision, double vision or loss of peripheral vision

- Gradual loss of sensation or movement in an arm or a leg

- Difficulty with balance

- $\quad$ Speech difficulties 
- Confusion in everyday matters

- Personality or behavior changes

Brain cancer is one of the cause of brain tumor that anyone can be affected by anytime. There are many kinds of brain tumors but two are main as benign tumors and another are malignant tumors. But in begin tumors there are no cancer cells whereas in malignant tumors cancer cells can be broken down and can easily spread to other parts of the brain even the entire body [2].

The brain images have different size and shapes where the proposed system measure the feature as the percentage of black pixels of the slicing binary images from feature (1-17), GLCM(Gray Level Co-occurrence Matrix) features included Contrast, Correlation, Angular Second Moment (ASM), Inverse Difference Moment (IDM) from feature (18-22), Entropy, Moment feature (24-31), mean, standard deviation, Correlation -coefficient.

\section{RESEARCH APPROACH}

For doing overall work the following architecture has been followed as-

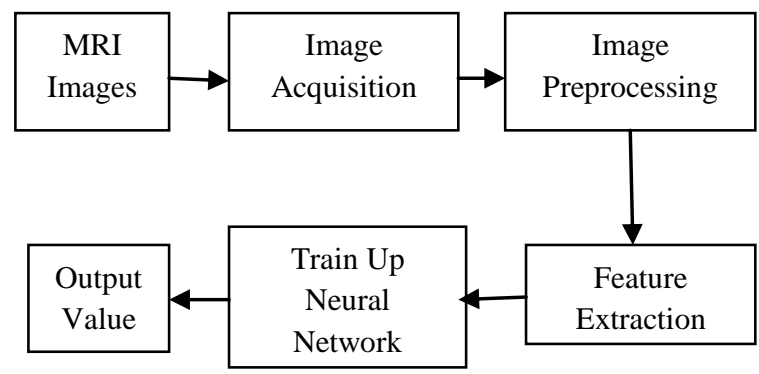

Fig 2: System Architecture of detecting MRI images

For image preprocessing the following operation which has been followed as:

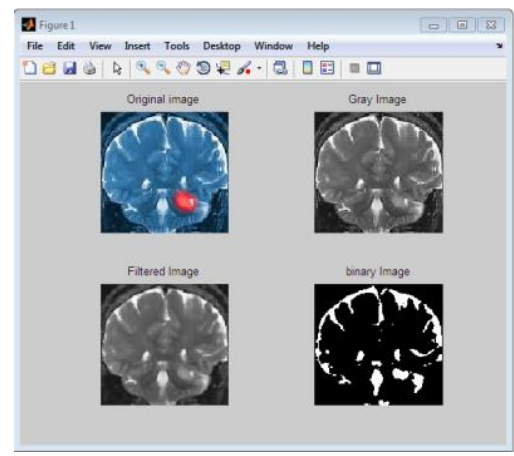

Fig 3: Performing image preprocessing

The MRI images are taken from National Cancer Institute, Apollo Cancer Society and American Cancer Institute. As MR imaging gives the proper condition of the brain tumor which is the most important stage of the brain cancer [3].

\section{FEATURE EXTRACTION}

Feature extraction is a way by which one can perform any operation to recognize the images with features as it works with a large set of data or value and give an standard combination without any difficulty [6]. This proposed method use Slicing image feature during binarization, GLCM feature
[4] [5] [6], Entropy [4] [5] [6], Moment feature, area [1] ,mean, standard deviation, correlation coefficient.

\subsection{GLCM Features}

Gray Level Co-occurrence Matrix is a method for extracting the second order features. It requires a large number of matrix which provides accuracy for the image estimination. It also represents the specified spatial relationship between pixels [6].GLCM feature used to get better texture from an image.

To create GLCM the graycomatrix function is used as it uses scalling to reduce the number of intensity value in an image to eight. Syntax is:

glcm = graycomatrix $(\mathrm{I})$

But to derive statistics from GLCM, the graycoprops function is used as it provides information about the texture of an image.

Syntax is:

stats $=$ graycoprops $($ glcm, properties $)$

stats is a structure with fields that are specified by properties.

graycoprops functions provide information as:

- Contrast: Requires the local variance in the GLCM. Range $=\left[0(\operatorname{size}(\mathrm{GLCM}, 1)-1)^{\wedge} 2\right]$ Contrast is 0 for a constant image.

$$
\text { Contrast }=\sum_{n=0}^{G-1} n^{2}\left\{\sum_{i=1}^{G} \sum_{j=1}^{G} P(i, j)\right\},|i+j|=n(1)
$$

- Correlation: Requires the joint probability occurrence of the specified pixels. Range $=\left[\begin{array}{ll}-1 & 1\end{array}\right]$; If Correlation is 1 positive relation if correlation -1 negative relation if correlation is 0 there is no relation between pixel of image.

$$
\text { Correlation }=\frac{\sum_{i=0}^{N g-1} \sum_{j=0}^{N g-1}(i, j) p(i, j)-\mu_{x} \mu}{\sigma_{x} \sigma_{y}}
$$

- Inverse Difference Moment (IDM): IDM also known as homogeneity. Measures the closeness of the distribution elements of GLCM Range = [0 1 1 . Homogeneity is 1 for a diagonal GLCM.

$$
I D M=\frac{\sum_{i=0}^{N g-1} \sum_{j=0}^{N g-1} P_{i j}}{1+(i-j)^{2}}
$$

- Angular Second Moment: Angular second moment also known as energy. It returns the sum of squared elements in the GLCM. It also measures the homogeneity of the images. Range $=\left[\begin{array}{ll}0 & 1\end{array}\right]$ Energy is 1 for a constant image.

$$
A S M=\sum_{i=0}^{N g-1} \sum_{j=0}^{N g-1} P^{2_{i j}}
$$

Entropy: It shows the amount of image information.

$$
\text { ENTROPY }=\sum_{i=0}^{N g-1} \sum_{j=0}^{N g-1}-P_{i j} * \log P_{i j}
$$

These five features are estimated using mathlab in image processing toolbox. So the mathlab code [6] for finding GLCM feature is: 
I =imread ('C:IUsers\Desktoplimage.jpg');

figure, imshow (i);

bw $=\mathrm{im} 2 \mathrm{bw}(\mathrm{i})$;

figure, imshow(bw);

glcms = graycomatrix $(\mathrm{bw})$;

stats.Contrast $=$ graycoprops $(\mathrm{glcms},($ 'Contrast')

stats.Homogeneity=graycoprops $($ glcms,('Homogeneity'))

stats.Correlation=graycoprops $($ glcms, ('Correlation'))

stats.Energy=graycoprops $($ glcms,('Energy'))

stats.ent=entropy $(\mathrm{bw})$;

\subsection{Moment Features}

For an image processing, image moment is a certain particular weighted average(moment)of the image pixels' intensities, or a function of such moments. By the methodology the properties can be concluded as area (or total intensity), centroids and information of its orientation.

For $\mathrm{f}(\mathrm{x}, \mathrm{y})$ 2-dimntional function of $\mathrm{M} \times \mathrm{N}$ binary image, the moment of order $(p+q)$ is defined by:

$m_{p q}=\sum_{x=1}^{M} \sum_{y=1}^{N}(x)^{p}(y)^{q} f(x, y)$

Where $\mathrm{p}, \mathrm{q}=0,1,2,3 \ldots \ldots \ldots \ldots$

Central moment obtains by following equation:

$\mu_{p q}=\sum_{x} \sum_{y}(x-\bar{x})^{p}(y-\bar{y})^{q} f(x, y)$

Where $\bar{x}=\frac{m_{10}}{m_{00}}$ and $\bar{y}=\frac{m_{01}}{m_{00}}$

For scaling normalization the central moment changes as following equation:

$\mu_{p q}=\frac{\mu_{p q}}{\mu_{00}^{\gamma}}$

where $\gamma=\left[\frac{(p+q)}{2}\right]+1$

seven values, computed by normalizing central moments through order three, that are invariant to object scale, position, and orientation. In terms of the central moments, the seven moments are given as,

$M_{1}=\eta_{20}+\eta_{02}$

$M_{2}=\left(\eta_{20}-\eta_{02}\right)^{2}+4 \eta_{11}^{2}$

$M_{3}=\left(\eta_{30}-3 \eta_{12}\right)^{2}+\left(3 \eta_{21}-\eta_{03}\right)^{2}$

$M_{4}=\left(\eta_{30}+\eta_{12}\right)^{2}+\left(\eta_{21}+\eta_{03}\right)^{2}$

$M_{5}=\left(\eta_{30}-3 \eta_{12}\right)\left(\eta_{30}+\eta_{12}\right) \mid\left(\eta_{30}+\eta_{12}\right)^{2}-$

$3 \eta 21+\eta 032+3 \eta 21-\eta 03 \eta 21+\eta 033 \eta 30+\eta 122-\eta 21+\eta 03$

2(13)

$\left.M_{6}=\left(\eta_{20}-\eta_{20}\right) \mid\left(\eta_{30}+\eta_{12}\right)^{2}-\left(\eta_{21}+\eta_{03}\right)^{2}\right\rfloor+$

$4 \eta_{11}\left(\eta_{30}+\eta_{12}\right)\left(\eta_{21}+\eta_{03}\right)$

$$
\begin{aligned}
& M_{7}=\left(3 \eta_{21}-\eta_{03}\right)\left(\eta_{30}+\eta_{12}\right) \mid\left(\eta_{30}+\eta_{12}\right)^{2}- \\
& 3 \eta 21+\eta 032-\eta 30+3 \eta 12 \eta 21+\eta 033 \eta 30+\eta 122-\eta 21+\eta 03 \\
& 2
\end{aligned}
$$

Area: Measures the total area of the binarization images by using bwarea [1] .

Syntax: total $=$ bwarea $(\mathrm{bw})$

Where total is a value that measures the total number of pixels in the image

Mean: Computes the mean of the value in an image.

Standard Deviation: Returns the standard deviation of the value in an image.

Correlation Coefficient: Returns the relation between the original image and the same processed filtered image.

\subsection{Splitting Image Features}

Splitting means division of an image into various types or shapes. In this experiment the following task has been performed as:

- At first, the images are splitted into two parts on the basis of horizontal approach, after doing it the percentage of black pixels of left and right portion of the images has been calculated.

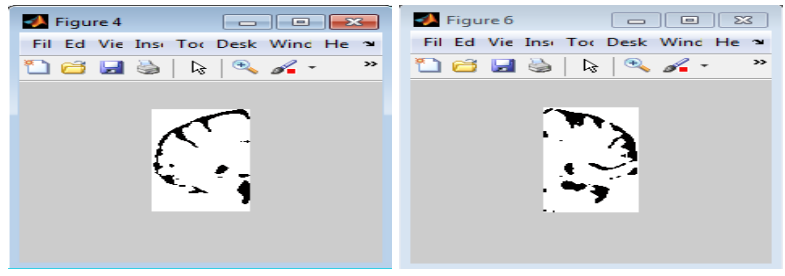

Fig 4: Image splitting into horizontal approach

- Then images are splitted into two in vertical approaches and easily measure the percentage of black pixels of the down and top portion of images.

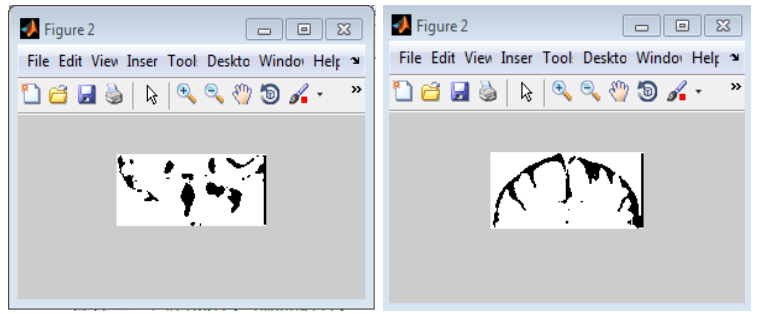

Fig 5: Image splitting into vertical approach

- After doing this the hole images are divided into four division then compute the percentage of black pixels of upper left, upper right, lower left, lower right portions. 

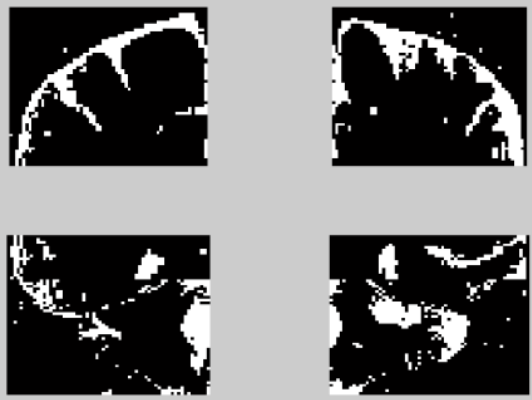

Fig 6: Image divided into four divisions

- $\quad$ Computing those operation, images are divided into $3 * 3$ matrix then compute the percentage of black pixels of different parts.

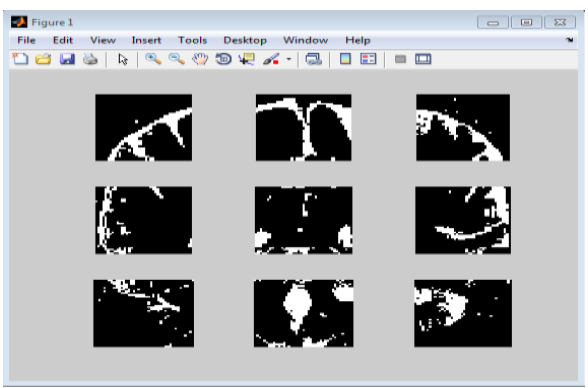

Fig 7: Splitting binary image into $3 * 3$ matrix

\section{DESIGN AND IMPLEMENTATION}

For designation the Neural Network has been established with input, hidden layer and output layer [5].

Where input is the number of features and in the output layer use one yes or no.

\subsection{Network Design}

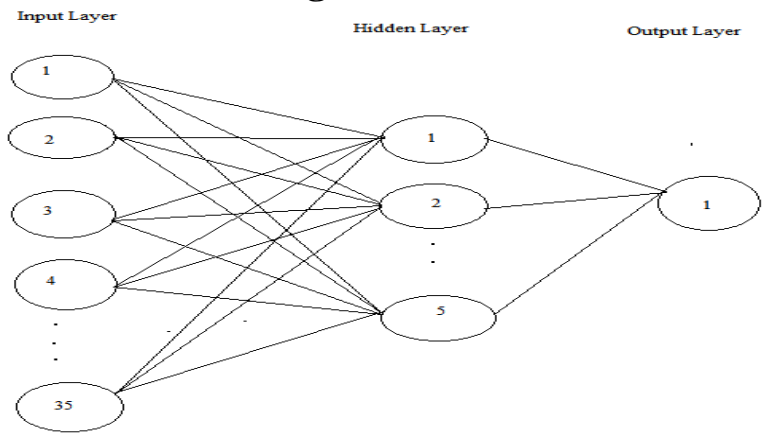

Fig 8: Network design of the proposed network

For parameter setting the following value has been setteled as:

Table 1: Parameter Setting

\begin{tabular}{|c|c|}
\hline Parameter & Value \\
\hline Input Layer & 35 \\
\hline $\begin{array}{c}\text { Hidden } \\
\text { layer }\end{array}$ & 5 \\
\hline \begin{tabular}{c} 
Output layer \\
\hline $\begin{array}{c}\text { Learning } \\
\text { rate }\end{array}$
\end{tabular} & .0001 \\
\hline
\end{tabular}

\begin{tabular}{|c|c|}
\hline $\begin{array}{c}\text { Total } \\
\text { number of } \\
\text { epochs }\end{array}$ & 1000 \\
\hline $\begin{array}{c}\text { Performance } \\
\text { goal }\end{array}$ & .0000001 \\
\hline Momentum & .9 \\
\hline
\end{tabular}

To detect MRI brain image the used tool is MATLAB, which is a high performance language for computing.

It is the standard instructional tool for high-productivity research, development and analysis. Toolboxes allow learning and applying specialized technology. So for developing this system has been used MATLAB.

\subsection{Classification}

As for classification many other technique exists in neural network as Artificial Neural Network, Support Vector

Machine. But the system use Artificial Neural Network as Feed forward Back Propagation Technique as feed forward back propagation subtracts the training output from the target (desired answer) to obtain the error signal. It then goes BACK to adjust the weights and biases in the input and hidden layers to reduce the error.

Training Class: 02

Targets: 0.1 Class-1: Cancer

Targets: 0.9 Class-2: Non-Cancer

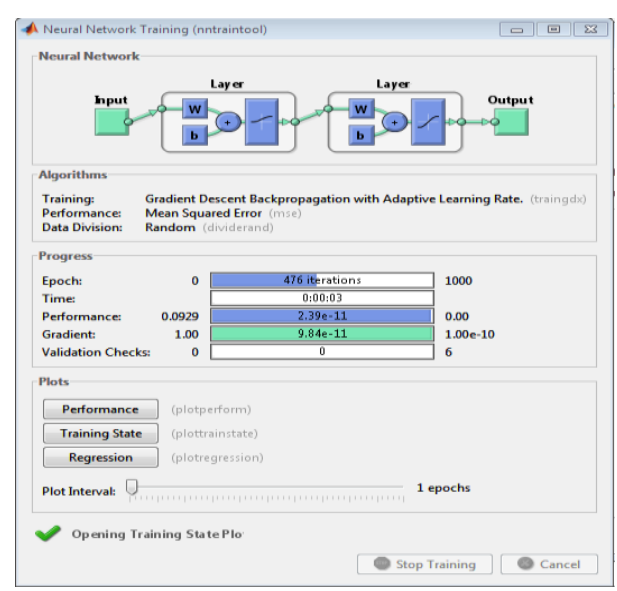

Fig 9: Training the Neural Network

\subsection{Research Result}

At first all the values of cancer and non-cancer images are trained in neural network. Then trained network will be tested with the some known values. Finally, some unknown values examined in the trained network to get the result and accuracy.

Table 2: Testing with known cancerous brain images

\begin{tabular}{|c|c|c|c|c|}
\hline $\begin{array}{c}\text { Group } \\
\text { of } \\
\text { image }\end{array}$ & $\begin{array}{c}\text { No. of } \\
\text { image }\end{array}$ & $\begin{array}{c}\text { Correct } \\
\text { recognition }\end{array}$ & $\begin{array}{c}\text { Error } \\
\text { recognition }\end{array}$ & Accuracy \\
\hline $\begin{array}{c}\text { Group } \\
1\end{array}$ & 7 & 7 & 0 & $100 \%$ \\
\hline
\end{tabular}




\begin{tabular}{|c|c|c|c|c|}
\hline $\begin{array}{c}\text { Group } \\
2\end{array}$ & 13 & 12 & 1 & $92.30 \%$ \\
\hline $\begin{array}{c}\text { Group } \\
3\end{array}$ & 9 & 9 & 0 & $100 \%$ \\
\hline Total & 29 & 28 & 1 & $96.55 \%$ \\
\hline
\end{tabular}

Table 3: Testing with known non-cancerous brain images

\begin{tabular}{|c|c|c|c|c|}
\hline $\begin{array}{c}\text { Group } \\
\text { of } \\
\text { image }\end{array}$ & $\begin{array}{c}\text { No. of } \\
\text { image }\end{array}$ & $\begin{array}{c}\text { Correct } \\
\text { recognition }\end{array}$ & $\begin{array}{c}\text { Error } \\
\text { recognition }\end{array}$ & Accuracy \\
\hline $\begin{array}{c}\text { Group } \\
1\end{array}$ & 12 & 12 & 0 & $100 \%$ \\
\hline $\begin{array}{c}\text { Group } \\
2\end{array}$ & 15 & 13 & 2 & $86.67 \%$ \\
\hline $\begin{array}{c}\text { Group } \\
3\end{array}$ & 11 & 10 & 1 & $90.90 \%$ \\
\hline Total & 38 & 35 & 3 & $92.11 \%$ \\
\hline
\end{tabular}

Table 4: Testing with unknown brain images

\begin{tabular}{|c|c|c|c|c|c|}
\hline $\begin{array}{c}\text { Gro } \\
\text { up of } \\
\text { imag } \\
\text { e }\end{array}$ & $\begin{array}{c}\text { No. } \\
\text { of } \\
\text { ima } \\
\text { ge }\end{array}$ & $\begin{array}{c}\text { Correct } \\
\text { recogniti } \\
\text { on }\end{array}$ & $\begin{array}{c}\text { Error } \\
\text { recogniti } \\
\text { on }\end{array}$ & $\begin{array}{c}\text { Accura } \\
\text { cy }\end{array}$ & Decision \\
\hline $\begin{array}{c}\text { Grou } \\
\text { p 1 }\end{array}$ & 15 & 14 & 1 & $93.33 \%$ & $\begin{array}{c}\text { Cancer/N } \\
\text { on-cancer }\end{array}$ \\
\hline $\begin{array}{c}\text { Grou } \\
\text { p 2 }\end{array}$ & 13 & 13 & 0 & $100 \%$ & Cancer \\
\hline $\begin{array}{c}\text { Grou } \\
\text { p 3 }\end{array}$ & 9 & 9 & 0 & $100 \%$ & Cancer \\
\hline $\begin{array}{c}\text { Grou } \\
\text { p 4 }\end{array}$ & 10 & 9 & 1 & $90 \%$ & $\begin{array}{c}\text { Cancer/N } \\
\text { on-cancer }\end{array}$ \\
\hline $\begin{array}{c}\text { Tota } \\
\text { l }\end{array}$ & 47 & 45 & 2 & $95.75 \%$ & Cancer \\
\hline
\end{tabular}

- In the table 2 some known cancerous images are taken and after testing them the approximate result is (.1) that indicates the cancerous image.

- In the table 3 some non-cancerous images are taken then testing them the approximate result is (.9) that indicates the non-cancerous image.

- In the table 4 some unknown brain images are taken then testing them if the result is .1 then it indicates the cancerous image and if .9 then non-cancerous image.

Compare with the existing system

The proposed system provides more accurate result compare than other existing system as the system measures only based on the features and trained by the neural network and the comparison shown in the following Table which is very clear.
Table 5: Compare with existing system

\begin{tabular}{|c|c|}
\hline Existing System & Accuracy \\
\hline $\begin{array}{l}\text { A Survey on Detecting Brain } \\
\text { Tumor in MRI Images Using } \\
\text { Image Processing Techniques[9] }\end{array}$ & $92 \%$ \\
\hline $\begin{array}{l}\text { Brain Tissue Classification in } \\
\text { Magnetic Resonance Images[4] }\end{array}$ & $91.5 \%$ \\
\hline Proposed System & $\mathbf{9 4 . 7 4 \%}$ \\
\hline
\end{tabular}

\section{LIMITATION}

This proposed system can only detect which is the cancerous and which is the non-cancerous image by extracting the image features that is trained by neural network but do not detect the cancer cell or types of cancer. So, these are the limitation of the system.

\section{FUTURE WORK}

- In future, the future work will be the detection of other cancer image as lungs, skin, eye etc.

- Can be used Support Vector Machine so that we can increase the accuracy and overcome the limitations.

\section{CONCLUSION}

The major achievement of this thesis is that it can recognize the cancer from MRI brain images. There is also a big advantage of this system is that it can work different image size. Overall detection rate of the system is $\mathbf{9 4 . 7 4 \%}$ which meet the satisfaction of my thesis.

Thanks to the experts who have contributed towards development of the template.

\section{REFERENCES}

[1] M.Karuna, "AUTOMATIC DETECTION AND SEVERITY ANALYSIS OF BRAIN TUMORS USING GUI IN MATLAB," International Journal of Research in Engineering and Technology, vol. 02, no. 10, pp. 586594, 2013.

[2] S. Z. Oo, "BRAIN TUMOR DETECTION AND SEGMENTATION USING WATERSHED SEGMENTATION AND MORPHOLOGICAL OPERATION," International Journal of Research in Engineering and Technology, vol. 03, no. 03, pp. $367-$ 374, 2014.

[3] D. Bhattacharyya and T. Kim, "Brain Tumor Detection Using MRI Image Analysis," in Ubiquitous Computing and Multimedia Applications, T. Kim, H. Adeli, R. J. Robles, and M. Balitanas, Eds. Springer Berlin Heidelberg, 2011, pp. 307-314.

[4] "Brain Tissue Classification in Magnetic Resonance Images | Yazdani | Jurnal Teknologi." [Online]. Available: 
http://www.jurnalteknologi.utm.my/index.php/jurnaltekn ologi/article/view/3879. [Accessed: 14-Nov-2015].

[5] "GLCM Textural Features for Brain Tumor Classification." [Online]. Available: http://connection.ebscohost.com/c/articles/77651099/glc m-textural-features-brain-tumor-classification. [Accessed: 14-Nov-2015].

[6] "Image Texture Feature Extraction Using GLCM Approach | IJSRP February 2013 Publication.” [Online]. Available: $\quad$ http://www.ijsrp.org/research-paper0513.php? $\mathrm{rp}=\mathrm{P} 171166$. [Accessed: 14-Nov-2015].

[7] "A Cluster Based Segmentation of Magnetic Resonance Images for Brain Tumor Detection - ResearchGate."
[Online]. Available:

http://www.researchgate.net/publication/236662023_A_ Cluster_Based_Segmentation_of_Magnetic_Resonance_ Images_for_Brain_Tumor_Detection. [Accessed: 14Nov-2015].

[8] B. P. Sanjeev Jain, "Cancer Cells Detection Using Digital Image Processing Methods," International Journal of Latest Research in Science and Technology, vol. VOLUME 3, no. 4, pp. 45-49, 2014.

[9] Aswathy, S.U., G. Glan Deva Dhas, and S.S. Kumar. "A Survey on Detection of Brain Tumor from MRI Brain Images." In 2014 International Conference on Control, Instrumentation, Communication and Computational Technologies (ICCICCT), 871-77, 2014. doi:10.1109/ICCICCT.2014.6993081. 